\title{
PREDICTION OF BEHAVIOUR OF PRESTRESSED SUSPENSION BRIDGE WITH TIMBER DECK PANELS
}

\author{
Vadims Goremikins $^{1 凹}$, Dmitrijs Serdjuks², Karina Buka-Vaivade ${ }^{3}$, Leonids Pakrastins ${ }^{4}$, \\ Nikolai Vatin 5 \\ 1, 2, 3, 4 Institute of Structural Engineering and Reconstruction, Riga Technical University, \\ Kipsalas st., 6A/6B, Riga 1048, Latvia \\ ${ }^{5}$ Saint-Petersburg State Polytechnical University, Polytechnicheskaya, 29, St. Petersburg 195251, Russian Federation \\ E-mails: ${ }^{1}$ vadims.goremikins@rtu.lv; ${ }^{2}$ dmitrijs.serdjuks@rtu.lv; ${ }^{3}$ karina.buka-vaivade@rtu.lv; \\ ${ }^{4}$ leonids.pakrastins@rtu.lv; ${ }^{5}$ vatin@mail.ru
}

\begin{abstract}
Cable truss usage allows developing bridges with reduced requirements for girder stiffness, where overall bridge rigidity is ensured by prestressing of the stabilization cable. The advantages of prestressed suspension trusses to provide required stiffness without massive stiffness girders and the ability of cross-laminated timber to behave in both directions are combined in the analysed structure. Prestressed cable truss with coincident (unclear meaning, difficult to translate) in the centre point of the span main and stabilization cables and vertical suspenders only was considered as the main load carrying system in the considered structure of suspension bridge. Two numerical models evaluated influence of cross-laminated timber deck on the behaviour of prestressed cable truss. Two physical models of the structure with the span equal to $2 \mathrm{~m}$ were developed for verification of the numerical models. The first physical model was developed for the case, when panels of the deck are placed without clearances and behaving in the longitudinal direction in compression so as in the transversal direction in bending. The second physical model was developed for the case when panels of the deck are placed with clearances and are behaving in the transverse direction in bending only. The dependences of maximum vertical displacements and horizontal support reaction of the cable truss on the intensity of vertical load in cases of symmetric and unsymmetrical loading were obtained for both physical models. Possibility to decrease the cable truss materials consumption by $17 \%$ by taking into accountcombined work of prestressed cable trusses and cross-laminated timber panels was stated.
\end{abstract}

Keywords: cross-laminated timber, kinematic displacements, numerical modelling, prestressed cable truss, scaled physical model, timber panel deck, unsymmetrical load.

\section{Introduction}

One of the possible ways to solve the problem of limited raw material and energy resources is an increasing in structural efficiency, obtained by using of renewable structural materials and decreasing the structural dead weight, increasing of span and durability of load carrying structures. Suspension cable structures are efficient structures for long span bridges (Goremikins et al. 2015; Walther et al. 1999). Increased deformability, mainly caused by kinematic displacements, is one of the leading disadvantages of suspension bridges (Sandovič et al. 2017). The problem of increased kinematic displacements is usually solved by adding of cantledge, increasing of girder stiffness, decreasing of loadbearing cable camber, application of diagonal suspenders or inclined additional cables, application of two chain systems, rigid cables or stress ribbons (Juozapaitis et al. 2015). Another efficient way to decrease kinematic displacements is the application of prestressed cable trusses (Goremikins et al. 2012; Serdjuks, Rocens 2004). Base parts of the cable truss are main load carrying cable, stabilisation cable and lattice elements such as suspenders or struts (Chen, Duan 2014).

Different types of cable trusses are known, such as convex cable trusses, convex-concave cable trusses and cable trusses with centre compression strut or parallel cable truss (Schierle 2012). However, one of the most efficient and convenient for application for bridges is the concave cable truss (Goremikins et al. 2012). Cable truss usage allows developing bridges with reduced requirements for girder stiffness, where the prestressing of the stabilization cable (Strasky 2011) ensures the overall bridge rigidity. It is possible to make the deck of lightweight composite materials in this case (Hambly 1998). 
The preliminary calculation showed that the structure with coincident loadbearing and stabilization cables in the centre of a span allows decreasing kinematic displacements in case of unsymmetrical load almost twice in comparison to the structure where the loadbearing and stabilisation cables are non-coincident. The appropriate level of prestressing so as the initial camber of main or stabilization cables allows limiting the kinematic displacements of the prestressed structure. Different types of the lattice possess only inessential improvements in kinematic displacements.

Therefore, prestressed cable truss with coincident in the centre point of the span main and stabilization cables and vertical suspenders only was considered as the primary load carrying system in the considered structure of suspension bridge. The suspension bridge is considered as an object of investigations because these structures are essential for road infrastructure in the Baltic region (Fig. 1).

Timber is used for bridge structures for a long time (Fu et al. 2014; Junior 1996). The most common types of timber bridges are beam, truss or arch type bridges, and modern stress-laminated-timber bridges (Ekholm, Kliger 2014; Fu et al. 2014; Junior 1996). Timber stiffness girders and timber towers are used as structural components of suspension bridges. Cross-laminated timber (CLT) is modern, environment friendly renewable material, which is used for load-bearing walls and panels in multi-storey timber buildings (Brandner 2013; Smith 2011). Cross-laminated timber is orthotropic structural material, which possesses a potential for behaviour in both directions $(\mathrm{Bu}-$ ka-Vaivade et al. 2017). Cross-laminated timber deck is used for steel bridges since the beginning of the $21^{\text {st }}$ century in Austria and continues to the present day in many countries (Divekar 2016; Fu et al. 2014; Mandegarian, Milev 2010). Cross-laminated timber deck works in one direction, in bending perpendicular to bridge span. The novel approach to use CLT deck in both directions - in the transversal direction in bending and in the longitudinal direction in compression of a prestressed suspension bridge is suggested in this research. The advantage of prestressed suspension trusses to provide required stiffness without massive stiffness girders and the ability of cross-laminated timber to behave in both directions are combined in the analysed structure.

Influence of the behaviour of bridge deck elements and cladding of the cable roofs on the behaviour of cable trusses and cable nets is neglected in the most investigations. However, it was stated that in some cases the behaviour of elements of cladding significantly effecting the distribution of internal forces acting in the cables of supporting structure. Influence of the timber cladding consisting of three layers of the deck, which were joined together by the compliant bonds under the angles $0^{\circ} / 90^{\circ} / 45^{\circ}$ on the behaviour of the saddle-shaped suspension cable roof was considered (Öiger 1991). The small-scale physical model described cladding and cable net behaviour, where the plywood sheets modelled timber cladding behaviour (Öiger 1991).
Suspension bridge with prestressed cable trusses with coincident in the centre point of the span main and stabilization cables and vertical suspenders only and deck consisting of the cross-laminated timber panels is close to the mentioned above cable roof by its working principle. Possibilities to decrease materials consumption of suspension bridge will be analysed by the evaluation of the influence of cross-laminated timber panel's deck on the behaviour of the prestressed cable trusses. Therefore, the paper aims to evaluate the influence of cross-laminated timber deck on the behaviour of prestressed cable truss in a suspension bridge. Two small-scale physical and FE models will describe the behaviour of the structure. The first physical model must be developed for the case when the panels of the deck are placed without clearances and behave in compression in the longitudinal direction of the bridge. The second physical model will be developed for the case when panels of the deck are placed with clearances and are working in one direction, which is perpendicular to the span of the bridge. The dependences of the intensity of vertical load on maximum vertical displacements and support reaction of the cable truss in cases of symmetric and unsymmetrical loading must be obtained for both physical models.

The physical models will verify the developed FEMs of a prestressed suspension bridge with timber deck. Plywood sheets will model the cross-laminated timber deck panels. The plywood sheets are supported at the bottom chords of the prestressed cable trusses. The possibility to decrease materials consumption for the considered structure of prestressed suspension bridge will be evaluated.

\section{Development of physical models of suspension bridge structure}

\subsection{Description of physical models}

Two small-scale physical models were constructed to investigate the behaviour of the prestressed cable truss and timber based deck in the considered structure of suspension bridge. The models are differed by the principle of deck behaviour. The deck is modelled by the plywood boards with a thickness equal to $6.5 \mathrm{~mm}$. In the first case, the plywood boards are placed with the clearances when the deck behaves in bending in the transversal direction of the bridge only (called in the further text as the first

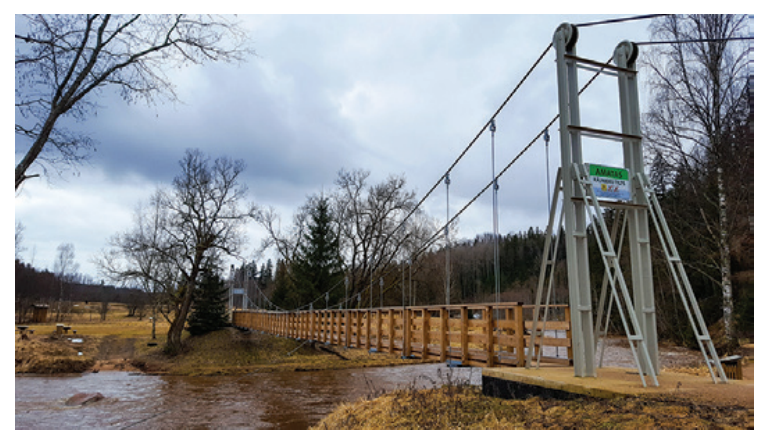

Fig. 1. Pedestrian suspension bridge over Amata River (Latvia) 
model). This case is widely used in the construction practice now. The first model is characterized by the relative simplicity of the design process of cross-laminated timber elements of the bridge deck. However, the layers of cross-laminated timber panels, which are placed in the

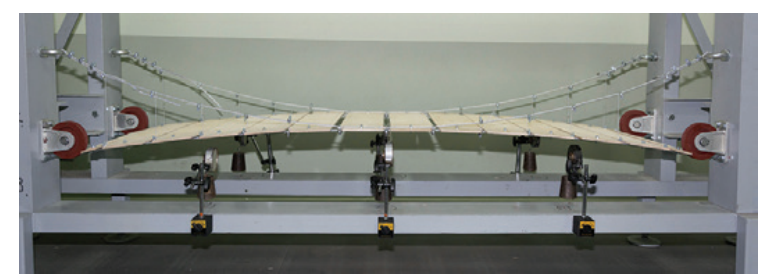

Fig. 2. Physical model, where plywood boards are placed with clearances and the deck behaves in bending in transversal direction only

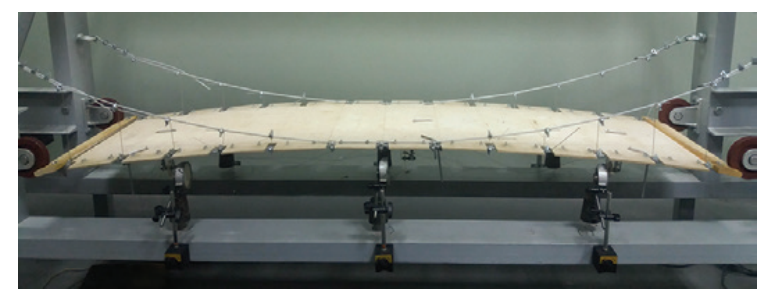

Fig. 3. Physical model, where plywood boards are placed without the clearances and the deck behaves in both directions

Table 1. Characteristics of cable elements of the physical models

\begin{tabular}{lcc}
\hline \multicolumn{1}{c}{ Elements } & Cable type & Diameter \\
\hline Main cable & $6 \times 19+$ WSC & $6.0 \mathrm{~mm}$ \\
Stabilization cable & $6 \times 19+$ WSC & $5.5 \mathrm{~mm}$ \\
Web elements & $6 \times 7+$ WSC & $1.5 \mathrm{~mm}$ \\
\hline
\end{tabular}

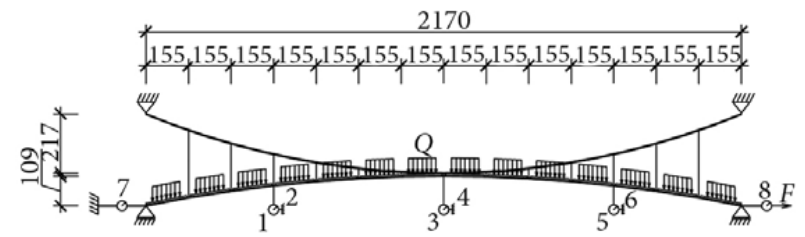

Fig. 4. Scheme of the suspension bridge physical models loading

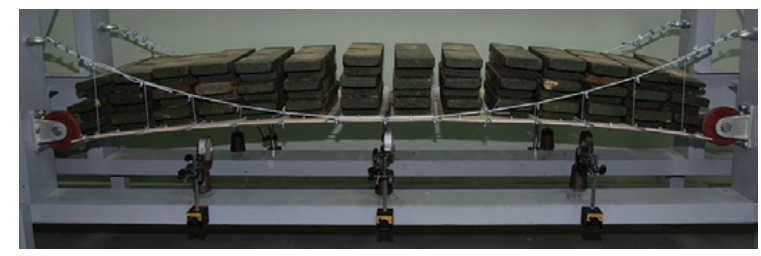

Fig. 5. Symmetrical load applied to the physical model of prestressed suspension bridge

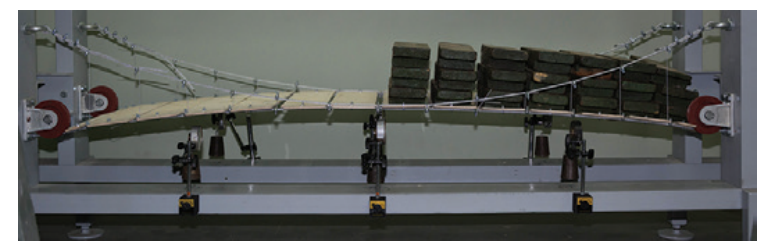

Fig. 6. Non-symmetrical load applied to the physical model of prestressed suspension bridge transversal direction, have low level of utilisation. The first model, where plywood boards are placed with clearances, is shown in the Fig. 2.

In the second case, the plywood boards are placed without clearances enabling the deck to behave in both directions: in bending in the transversal direction and compression in the direction parallel to the cable truss (the model is called as the second model in further text). The deck resists zero bending moments in the longitudinal direction. The second model, where plywood boards are placed without the clearances, is shown in the Fig. 3.

The span of the physical models of prestressed suspension bridges is equal to $2.17 \mathrm{~m}$. The main and the stabilisation cable camber is equal to $0.217 \mathrm{~m}$ and $0.109 \mathrm{~m}$, correspondingly. The width of the model is equal to $0.5 \mathrm{~m}$. Stabilization cables support the deck (Fig. 4). The structure is divided into 14 parts by suspenders. The deck is divided into 14 panels, which are modelled by the plywood boards. Only vertical coupling is provided between the stabilization cables and the deck panels and free sliding of the deck panels by cables is possible. The elements of the prestressed suspension bridges models are made of steel cables. The diameters of the elements are shown in Table 1. The design resistance of the cables is equal to $850 \mathrm{MPa}$. The cross-sections of the cables and prestressing level were specially designed so that the model of the bridge resists the load equal to $7.3 \mathrm{kN} / \mathrm{m}^{2}$. The ANSYS optimization tool was used to calculate appropriate prestressing level and cross-sections of the elements. The stress level in the cables was limited to $80 \%$ from design resistance, and deflection was limited to $1 / 200$ from the span.

\subsection{Process of physical models testing}

Both models were subjected to the action of static vertical loading and prestressing. The scheme of loads application to both models is shown in the Fig. 4.

The extension of cable structures is necessary to minimize non-elastic deformations, which are caused by the cables internal structure.

The prestressing is organized in stabilization cable. Based on the design the model was prestressed by load $9.05 \mathrm{kN}$ for each side. The deck was assembled after prestressing to model the assembly of the bridge in real circumstances. Two types of loading were applied to the models: symmetrical and non-symmetrical. The load was applied to the deck by placing steel weights with weight changing within limits from $17 \mathrm{~kg}$ to $20 \mathrm{~kg}$ each.

The experimental models were loaded up to the load equal to $7.30 \mathrm{kN} / \mathrm{m}^{2}$ with step $2.43 \mathrm{kN} / \mathrm{m}^{2}$ in symmetrical loading case (Fig. 5). The models were loaded up to the load $7.30 \mathrm{kN} / \mathrm{m}^{2}$ with step $2.43 \mathrm{kN} / \mathrm{m}^{2}$ placed to one-half of the span only in non-symmetrical loading case (Fig. 6).

Three pairs of mechanical deflectometers, which are shown in the Fig. 4, measured the vertical displacements in quarters and the middle of the span. Dynamometers measured the horizontal support reaction of stabilisation cables. 


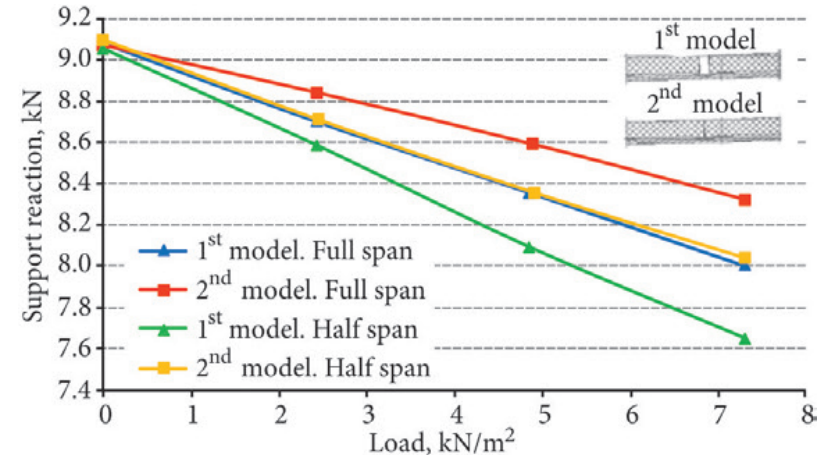

Fig. 7. Horizontal support reaction of stabilization cable depending on loading

\subsection{Results of physical models testing}

Symmetrical and non-symmetrical loads were applied to the models. The horizontal support reaction of stabilisation cable was measured during all load steps (Fig. 7). The results show that the support reaction was decreased less for the second model, meaning the loadbearing cable was loaded less, while the applied load was the same.

The maximum displacements in the case of symmetrical load were measured in the centre points of the model (points 3 and 4 on the left and right sides, respectively, Fig. 4). In case of unsymmetrical load, the maximum displacements of the model were calculated as the sum of measured displacements of points 1 and 5 for the left side and 5 and 6 for the right side. Non-loaded part is moving up and loaded part is moving down. The results of displacements are depicted in Figs 8-9.

\section{Description of numerical model}

Two numerical models of the structures were developed to describe the behaviour of the physical models. 3D numerical model described the behaviour of the structure with the deck behaving in both directions (the second model). The numerical model was developed using FEM software ANSYS 12 (Fig. 10). The cable elements were modelled using 3D spar element LINK10 with tension the only function. The deck was modelled by 3D layered shell element SHELL181. The deck was coupled to the cables in vertical $(z)$ and transversal direction $(y)$ only. The cables and the deck were uncoupled in the longitudinal direction $(x) .2 \mathrm{D}$ numerical model described the behaviour of the structure with the deck behaving only in bending in transversal direction (the first model). Link elements were only used for the 2D model, and the load was applied in joints (Fig. 11).

The deck of both models is resisting zero moment in the longitudinal direction, as it is built from separate boards. Four loading steps were used to simulate the behaviour of the structure. The dead load was applied in the first step; the prestressing was applied in the second step; load to half span was applied in the third step, and loading to the full span was applied in the last step. KILL/ALLIVE commands modeled the process of assembling the deck after prestressing. The elements of the deck were deactivated in

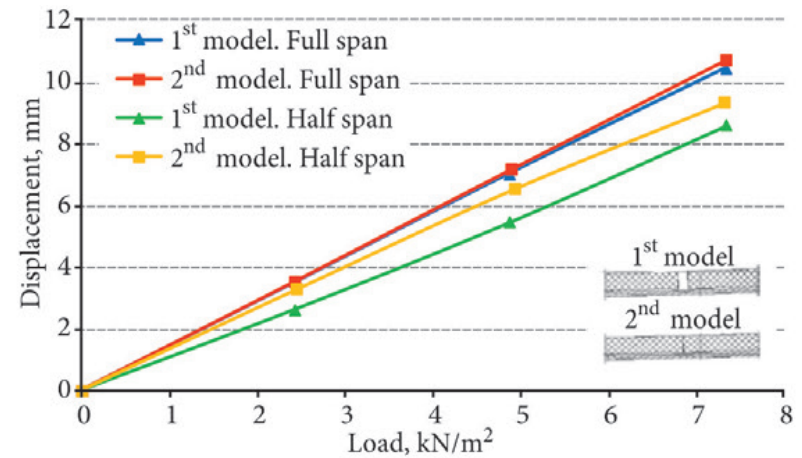

Fig. 8. Maximal displacements under different loading cases

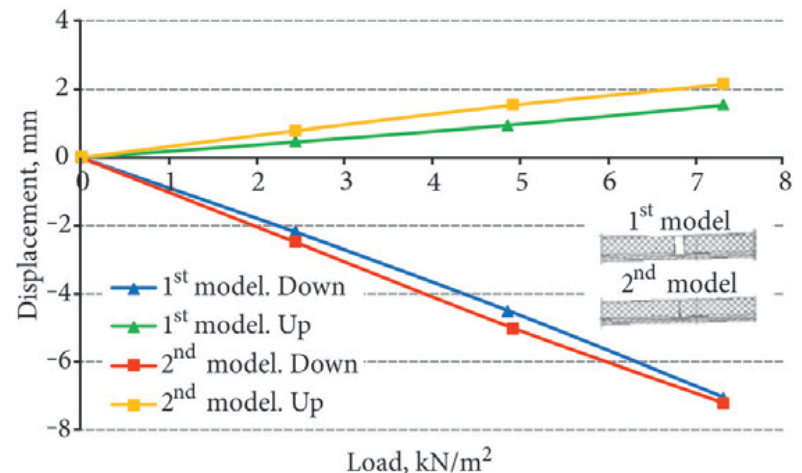

Fig. 9. Displacements under unsymmetrical load

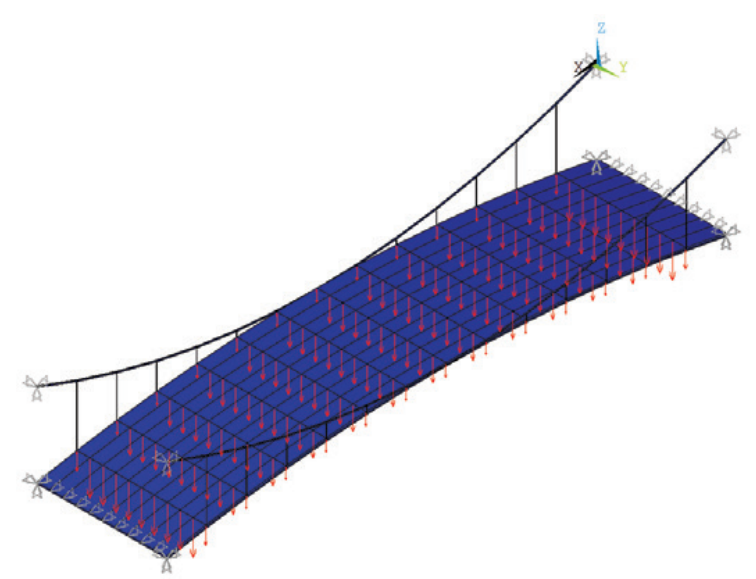

Fig. 10. 3D numerical model of the structure, where plywood boards are placed without the clearances and the deck behaves in compression in longitudinal direction and in bending in transversal direction

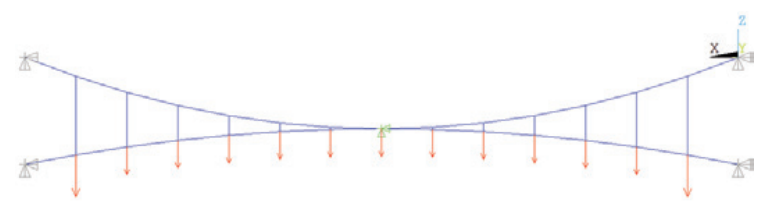

Fig. 11. 2D numerical model of the structure, where plywood boards are placed with the clearances and the deck behaves in bending in transversal direction only 
the prestressing load step by EKILL command and then activated by EALIVE command (ANSYS 12.1 Mechanical APDL Manual).

The prestressing of the model was realized in the numerical model using temperature difference and thermal extension option. In this case, the numerical model behaviour is more stable, compared to the definition of initial strains. Large displacement effects were taken into account by performing the geometrically nonlinear analyses.

The modulus of elasticity of the cables is a parameter, which depends on the level of initial extension (Feyrer 2015). The standard LVS EN 1993-1-11:2007. Eurocode 3: Design of Steel Structures - Part 1-11: Design of Structures with Tension Components recommends the modulus equal to $150 \mathrm{GPa}$. The previous researches showed that the modulus was equal to $60 \mathrm{GPa}$ (Goremikins et al. 2012). In this research, the modulus of elasticity of the cables was obtained using calibration of the first model and is equal to $105 \mathrm{GPa}$. Plywood boards with a thickness of $6.5 \mathrm{~mm}$ and length equal to $600 \mathrm{~mm}$ were considered as elements of the deck for both models. The width of the boards changes within limits from $70 \mathrm{~mm}$ to $160 \mathrm{~mm}$. The material properties of the plywood deck boards were assumed according to the manufacturer declaration of conformity. Therefore, characteristic

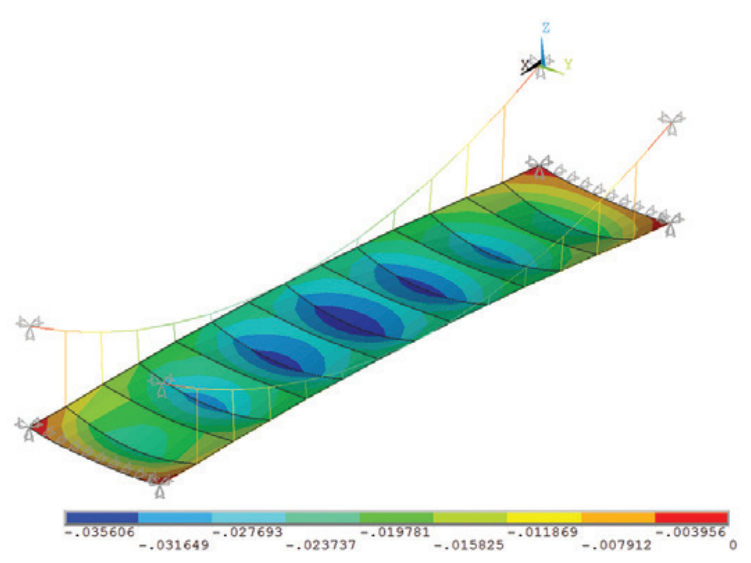

Fig. 12. Results of displacements and appearance of local effects of numerical model of the structure, where plywood boards are placed without the clearances and the deck behaves in compression and in bending values of moduli of elasticity in bending parallel and compression perpendicular to the fibres of outer layers were equal to $13101 \mathrm{MPa}$ and $7875 \mathrm{MPa}$, correspondingly.

\section{Suspension bridge structure with deck efficient in both directions}

Symmetrical and non-symmetrical loads were applied to the models. In the case of non-symmetrical loading, the loaded part of the deck moves downwards, but non-loaded part moves upwards. Local effects were observed during the physical model testing, so as in the numerical model, which caused differences in numerical simulations and experiment (Fig. 12). Results of the numerical simulation in comparison to experimental model testing are gathered in Table 2.

The results of the second experimental model testing indicate that horizontal support reaction of stabilization cable decreases by $8.1 \%$ for symmetrical load and $11.2 \%$ for unsymmetrical comparing to the unloaded model. For the first model the support reaction of stabilization cable decreases by $11.6 \%$ for symmetrical load and $15.5 \%$ for unsymmetrical.

In the case of symmetrical load, the maximum displacement is equal to $10.47 \mathrm{~mm}$ for the first model and $10.74 \mathrm{~mm}$ for the second. In the case of unsymmetrical load, the maximum displacement is equal to $8.60 \mathrm{~mm}$ for the first model and $9.36 \mathrm{~mm}$ for a second. It was noticed that in case of symmetrical load displacements are larger than in case of a unsymmetrical load. In previous researches (Goremikins et al. 2012), an opposite effect was observed when the loadbearing and stabilization were noncoincident in the centre point.

Designed FEM allows analysing the stresses in the models. For the first model, the stress distribution differs from $560 \mathrm{MPa}$ in the centre and $621 \mathrm{MPa}$ near the supports while in stabilisation cables stressed differs from $491 \mathrm{MPa}$ near the supports to $499 \mathrm{MPa}$ in the centre. The stresses in suspenders differ from $471 \mathrm{MPa}$ for the central suspenders to $483 \mathrm{MPa}$ for edge suspenders. For the second model, the stress distribution differs from $534 \mathrm{MPa}$ in the centre and $591 \mathrm{MPa}$ near supports while in stabilisation cables stressed differs from $503 \mathrm{MPa}$ near supports and $509 \mathrm{MPa}$ in the centre. The stresses in suspenders differ from $404 \mathrm{MPa}$

Table 2. Results of experimental model testing and numerical simulation

\begin{tabular}{|c|c|c|c|c|c|c|c|}
\hline \multicolumn{7}{|c|}{ Displacement of point, $\mathrm{mm}$} & \multirow{2}{*}{$\begin{array}{l}\text { Horizontal support reaction } \\
\text { of stabilization cable, } \mathrm{kg}\end{array}$} \\
\hline Type of results & $\begin{array}{l}\text { Variant of } \\
\text { model }\end{array}$ & $\begin{array}{l}\text { Variant of loading/ } \\
\text { Number of points }\end{array}$ & $\begin{array}{c}\text { Points } \\
3,4\end{array}$ & $\begin{array}{c}\text { Points } \\
1,2\end{array}$ & $\begin{array}{l}\text { Points } \\
5,6\end{array}$ & $\begin{array}{c}\text { Total, } \\
1+5,2+6\end{array}$ & \\
\hline \multirow{4}{*}{ Experiment results } & \multirow{2}{*}{$1^{\text {st }}$ model } & Symmetrical load & -10.47 & - & - & - & 800 \\
\hline & & Unsymmetrical load & & 1.54 & -7.06 & 8.60 & 765 \\
\hline & \multirow{2}{*}{$2^{\text {nd }}$ model } & Symmetrical load & -10.74 & - & - & - & 832 \\
\hline & & Unsymmetrical load & - & 2.15 & -7.21 & 9.36 & 804 \\
\hline \multirow{4}{*}{ Modelling results } & \multirow{2}{*}{$1^{\text {st }}$ model } & Symmetrical load & -10.39 & - & - & - & 731 \\
\hline & & Unsymmetrical load & - & 0.33 & -7.65 & 7.98 & 724 \\
\hline & \multirow{2}{*}{$2^{\text {nd }}$ model } & Symmetrical load & -9.54 & - & - & - & 746 \\
\hline & & Unsymmetrical load & - & 1.02 & -7.90 & 8.92 & 724 \\
\hline
\end{tabular}


to $487 \mathrm{MPa}$; there is no any order in stresses due to the local effects in the deck.

In case of unsymmetrical load, the distribution of stresses is different. For the first model, the stress distribution differs from $355 \mathrm{MPa}$ for the unloaded half-span to $561 \mathrm{MPa}$ for the loaded half-span while in stabilisation cables stresses differs from $486 \mathrm{MPa}$ for the loaded half-span to $624 \mathrm{MPa}$ for the unloaded half-span. The stresses in suspenders differ from $243 \mathrm{MPa}$ for the unloaded half-span to $460 \mathrm{MPa}$ for the loaded half-span. For the second model, the stress distribution differs from $333 \mathrm{MPa}$ for the unloaded half-span to $548 \mathrm{MPa}$ for the loaded half-span while in stabilisation cables stresses differs from $489 \mathrm{MPa}$ for the loaded half-span to $637 \mathrm{MPa}$ for the unloaded half-span. The stresses in suspenders differ from $228 \mathrm{MPa}$ for the unloaded half-span to $454 \mathrm{MPa}$ for the loaded half-span. It is concluded that the stresses in cables are smaller in case of the model with the deck acting in both directions.

To investigate the efficiency of usage of the deck behaving in both directions, two FEM were developed for the design example of the bridge: one with the deck behaving in both directions and the second behaving only in bending in the transversal direction. The span and width assumed to be equal to the $60 \mathrm{~m}$ and $5 \mathrm{~m}$, respectively. The cambers of main and stabilisation cables were assumed as $1 / 10$ and $1 / 20$ of the span, correspondingly. Cross-laminated timber panels were used as a deck and cables with a modulus of elasticity equal to $150 \mathrm{GPa}$ were used for the case study. The rational parameters of the two models were obtained using ANSYS optimisation engine. The objective function was material consumption of the cables, the stresses in the cables and maximal vertical displacements were assumed as state variables and, finally, the diameters of the cables and prestressing force were assumed as design variables. The obtained material consumption of the optimized structure with the deck behaving only in bending is equal to $4864 \mathrm{~kg}$, and the material consumption of the optimized structure with the deck behaving in both directions is equal to $4025 \mathrm{~kg}$. Therefore, usage of the deck behaving in the longitudinal direction in compression and in bending in a transverse direction allowing to decrease material consumption of the cables by $17.3 \%$, while the material consumption of the deck remains the same.

\section{Conclusions}

1. Influence of two different structures of timber panels deck on the behaviour of the prestressed cable truss in suspension bridge was evaluated. Possibility to decrease materials consumption of suspension bridge was analysed.

2. It was stated that timber panels deck behaving in bending in the transversal direction and compression in the direction parallel to the cable truss decreases internal forces in the loadbearing cables of the cable truss comparing to the structure with timber panels deck behaving in bending in transversal direction only. The corresponding decrease in materials consumption exceeds $17 \%$.
3. The dependences of maximum vertical displacements and support reaction of the cable truss on the intensity of vertical load in cases of symmetric and unsymmetrical loading were obtained by the physical models with the span $2 \mathrm{~m}$. It was stated that the displacement of the model where panels of the deck are placed without clearances is by $2.6 \%$ and $8.8 \%$ bigger than the displacements of the model where panels of the deck are placed with clearances in case of symmetrical and unsymmetrical load, respectively.

4. It was shown, that the developed numerical models allow predicting the behaviour of a prestressed suspension bridge with timber deck.

\section{Acknowledgements}

Support for this work was provided by the Riga Technical University through the Scientific Research Project Competition for Young Researchers No. ZP-2017/5.

\section{References}

Brandner, R. 2013. Production and Technology of Cross Laminated Timber (CLT): a State-of-the-Art Report, European Conference on Cross Laminated Timber (CLT). Ed. by Harris, R.; Ringhofer, A.; Schickhofer, G., 21-22 May 2013, Graz, Austria. 1-33.

Buka-Vaivade, K.; Serdjuks, D.; Goremikins, V.; Vilguts, A.; Pakrastins, L. 2017. Experimental Verification of Design Procedure for Elements from Cross-Laminated Timber, Procedia Engineering 172: 1212-1219. https://doi.org/10.1016/j.proeng.2017.02.142

Chen, W. F.; Duan, L. 2014. Bridge Engineering Handbook: Substructure Design. $2^{\text {nd }}$ edition, vol. 3. New York: CRC Press LLC. 722 p. https://doi.org/10.1201/b15621

Divekar, N. 2016. Introduction to New Material - Cross Laminated Timber, International Journal of Engineering Research 5(special 3): 675-679. https://doi.org/10.17950/ijer/v5i3/034

Ekholm, K.; Kliger, I. R. 2014. Effect of Vertical Interlaminar Shear Slip and Butt Joints in Narrow Stress-Laminated-Timber Bridge Decks, Engineering Structures 72: 161-170. https://doi.org/10.1016/j.engstruct.2014.03.023

Feyrer, K. 2015. Wire Ropes: Tension, Endurance, Reliability. $2^{\text {nd }}$ edition. Berlin: Springer-Verlag Berlin Heidelberg. 343 p. https://doi.org/10.1007/978-3-642-54996-0

Fu, M.; Liu, Y.; Li, N.; Zhang, Z.; Siviero, E. 2014. Application of Modern Timber Structure in Short and Medium Span Bridges in China, Journal of Traffic and Transportation Engineering (English Edition) 1(1): 72-80. https://doi.org/10.1016/S2095-7564(15)30091-X

Goremikins, V.; Rocens, K.; Serdjuks, D. 2012. Decreasing Displacements of Prestressed Suspension Bridge, Journal of Civil Engineering and Management 18(6): 858-866. https://doi.org/10.3846/13923730.2012.720936

Goremikins, V.; Rocens, K.; Serdjuks, D.; Pakrastins, L.; Vatin, N. 2015. Cable Truss Topology Optimization for Prestressed Long-Span Structure, Advances in Civil Engineering and Building Materials IV: 363-367. https://doi.org/10.1201/b18415-83

Hambly, E. C. 1998. Bridge Deck Behaviour. $2^{\text {nd }}$ edition. New York: E \& FN Spon. 308 p. 
Junior, C. C. 1996. Timber Bridges in South America, in Proc. of the National Conference on Wood Transportation Structures. Ed. by Ritter, M. A.; Duwadi, S. R.; Lee, P. H. D., 23-25 October 1996, Madison, U.S. Dept of Agriculture, Forest Service, Forest Products Laboratory. 27-38.

Juozapaitis, A.; Merkevičius, T.; Daniūnas, A.; Kliukas, R.; Sandovič, G.; Lukoševičienè, O. 2015. Analysis of Innovative Two-Span Suspension Bridges, The Baltic Journal of Road and Bridge Engineering 10(3): 269-275. https://doi.org/10.3846/bjrbe.2015.34

Mandegarian, A.; Milev, S. 2010. Cross Laminated Timber. Research Report No. Civil 510. University of British Columbia. 21 p.

Öiger, K. 1991. Analysis on the Structural Behaviour of Composite Saddle-Shape Roof Shells, Rakenteiden Mekaniikka 24(3): $11-27$.

Sandovič, G.; Juozapaitis, A.; Gribniak, V. 2017. Experimental and Analytical Investigation of Deformations and Stress Distribution in Steel Bands of a Two-Span Stress-Ribbon Pedestrian Bridge, Mathematical Problems in Engineering 2017: 1-11. https://doi.org/10.1155/2017/9324520
Schierle, G. G. 2012. Structure and Design. San Diego: Cognella. $624 \mathrm{p}$.

Serdjuks, D.; Rocens, K. 2004. Decrease the Displacements of a Composite Saddle-Shaped Cable Roof, Mechanics of Composite Materials 40(5): 437-442.

https://doi.org/10.1023/B:MOCM.0000047234.72813.2e

Smith, R. E. 2011. Interlocking Cross-Laminated Timber: Alternative Use of Waste Wood in Design and Construction, The Building Technology Educators' Society (BTES) Conference 2011. Ed. by Hui, V.; Boake, T. M., 4-7 August 2011, Toronto, Ontario, Canada. 1-8.

Strasky, J. 2011. Stress Ribbon and Cable Supported Pedestrian Bridge. $2^{\text {nd }}$ edition. London: ICE Publishing. 274 p.

https://doi.org/10.1680/srcspb.41462

Walther, R.; Houriet, B.; Isler, W.; Moia, P.; Klein, J. F. 1999. Cable Stayed Bridges. $2^{\text {nd }}$ edition. London: Thomas Telford. 236 p. https://doi.org/10.1680/csb.27732

Received 31 March 2017; accepted 07 September 2017 